\title{
The impact of His bundle pacing on left ventricle global longitudinal strain in heart failure patients with LBBB - a pilot study
}

\author{
(D)Marija Brestovac*, \\ (D)Jadranka Šeparović \\ Hanževački \\ (D) Martina Lovrić \\ Benčić, \\ (i)Richard Matasić
}

University of Zagreb School of Medicine, University Hospital Centre Zagreb, Zagreb, Croatia

RECEIVED:

March 28, 2021

ACCEPTED:

April 2, 2021

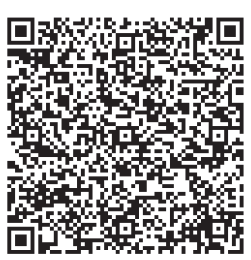

$\square$ Cardiologia Croatica 2021:16(5-6):204.
KEYWORDS: His bundle pacing, cardiac resynchronization therapy, global longitudinal strain. CITATION: Cardiol Croat. 2021;16(5-6):204. | https://doi.org/10.15836/ccar2021.204

*ADDRESS FOR CORRESPONDENCE: Marija Brestovac, Klinički bolnički centar Zagreb, Kišpatićeva 12, HR-10000 Zagreb, Croatia. / Phone: +385-99-7742-627 / E-mail: marija.brestovac@gmail.com

ORCID: Marija Brestovac, https://orcid.org/0000-0003-1542-2890 • Jadranka Šeparović Hanževački, https://orcid.org/0000-0002-3437-6407 Martina Lovrić Benčić, https://orcid.org/0000-0001-8446-6120 • Richard Matasić, https://orcid.org/0000-0003-1289-1704

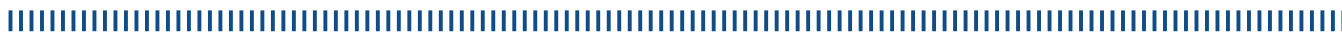

Introduction: His bundle pacing (HBP) is an alternative method for achieving resynchronization in patients with LBBB and heart failure (HF). HBP retains activation of the intrinsic electrical conduction system in non LBBB conduction and may improve LBBB conduction..$^{1-3}$ The aim of this pilot study was to compare the sucess of cardiac resynchronization therapy (CRT) between HBP (HBP-CRT) and standard biventricular CRT pacing as global longitudinal strain changes of the left ventricle (GLS) in HF patients with LBBB.

Patients and Methods: In this study 31 patients were included with HBP-CRT (group I) and 39 patients with standard CRT pacing using biventricular pacing (group II). The two groups were matched according to type of cardiomyopathy (CMP), NYHA status, left ventricular enddiastolic volume and gender (35\% ischemic CMP, 65\% dilated CMP, 25\% female). Each patient underwent an echocardiographic study (ECHO) including the assessment of LV myocardial deformation using two-dimensional speckle tracking before and within 3 months after implantation. The change in GLS within 3 months of CRT was compared between the two groups.

Results: Both groups, HBP-CRT ( $\mathrm{p}=0.048)$ and standard CRT $(\mathrm{p}=0.001)$ are associated with significant improvement in GLS within 3 months of CRT (Table 1). There were no significant differences between both groups in improvement in GLS ( $\mathrm{p}=0.395)$.

Conclusion: Improvement of GLS was present in HBP-CRT as well as standard CRT. No significant difference was found between the two methods of myocardial resynchronization in GLS change within 3 months of follow up. According to these results we could suggest that both resynchronization methods could be equally used as cardiac resynchronization therapy according to GLS measurement.

TABLE 1. Change in left ventricular global longitudinal strain within 3 months of cardiac resynchronization therapy between the analyzed groups.

\begin{tabular}{ccccccc}
\hline Group & N & GLS before CRT & GLS after CRT & $\Delta$ & SD & \\
\hline I (HBP-CRT) & 31 & -10.06 & -12.30 & 2.24 & 3.85 & $\mathbf{p}=\mathbf{0 . 0 4 8}$ \\
\hline II (standard CRT) & 39 & -7.24 & -9.73 & 2.48 & 3.90 & $\mathbf{p}=\mathbf{0 . 0 0 1}$ \\
\hline
\end{tabular}

HBP-CRT - His bundle pacing - cardiac resynchronization therapy, GLS - Left ventricle global longitudinal strain, $\Delta$ - mean GLS change between prior and after CRT, SD - standard deviation.

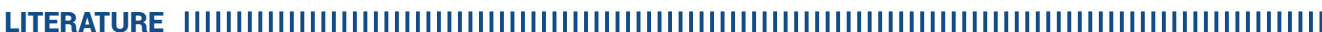

1. Lewis AJM, Foley P, Whinnett Z, Keene D, Chandrasekaran B. His Bundle Pacing: A New Strategy for Physiological Ventricular Activation. J Am Heart Assoc. 2019 Mar 19;8(6):e010972. https://doi.org/10.1161/JAHA.118.010972

2. Jung IH, Park JH, Lee JA, Kim GS, Lee HY, Byun YS, et al. Left Ventricular Global Longitudinal Strain as a Predictor for Left Ventricular Reverse Remodeling in Dilated Cardiomyopathy. J Cardiovasc Imaging. 2020 Apr;28(2):137-149. https://doi.org/10.4250/jcvi.2019.0111

3. Sharma PS, Vijayaraman P. His Bundle Pacing Or Biventricular Pacing For Cardiac Resynchronization Therapy In Heart Failure: Discovering New Methods For An Old Problem. J Atr Fibrillation. 2016 Dec 31:9(4):1501. https://doi.org/10.4022/jafib.1501 